\title{
Sharing Our Experience: A Joint Practicum Case Study
}

Opportunities to mentor library school students may seem like a remote possibility for a hospital library, especially when that library has no affiliation with a library school and/or if there is not a library school in the immediate geographic area. However, some library graduate school programs offer an online only or a blended option, so library students in the area may be seeking opportunities to gain experience and could benefit from such a mentorship, especially in health sciences libraries. The hospital library also may not have an abundance of staff, which presents challenges of how to coordinate a positive mentoring experience for the library and the student. This case study of two health sciences libraries, one public and the other private, will demonstrate how libraries with different user groups and resources collaborated on a practicum with a public service focus. This practicum may serve as a model for hospital librarians who want to mentor future librarians, and who believe they do not have the resources or time to do so on a solo or full-time basis.

\section{Literature Review}

Linda Smith (1) set up the framework for understanding the educational theories and efforts to improve health science librarian training. Smith concluded that there were five important aims to gaining the excellence in training the long-term sustainability of the profession, and one of those aims was to "[d] evelop opportunities for practicums, internships, and residencies at the cooperating medical schools and affiliated institutions, in health science libraries and information services for clinical care, that would allow better preparation in the areas of information integration and medical informatics."(1) 
Because research(2) shows that lack of teaching experience was listed as a top challenge to new resident librarians, the opportunity for teaching experiences was incorporated into the practicum as one of the areas of student focus. Another lesson comes from Sargent, Becker and Klingberg,(3) who analyzed the impact of academic library internships on participants. One of the survey findings was that the interns "never felt integrated into the library's organization. One intern said that she never felt like a part of the library as a whole.’(3) This survey finding was kept in mind during the planning stages as a situation to be avoided.

\section{The Settings}

The two libraries involved are notably different. The Library of the Health Sciences-Chicago (LHS) is the largest health sciences library in the Chicago area and is part of the University of Illinois at Chicago (UIC), a research institution. LHS is the Chicago health sciences campus library; the campus includes the 496-bed UIC Medical Center Hospital (UIMC) and Outpatient Care Center and other affiliated health care institutions. The Library of Rush University Medical Center (Rush) serves the communities of both Rush University, a private graduate health science institution, and the 676-bed Rush University Medical Center Hospital. Rush emphasizes patient care, having achieved the MAGNET status several times, while UIMC nurses have just begun the MAGNET process. Although geographically close to Rush, UIC caters to a higher percentage of minorities.(4) While LHS is a standalone building on campus, Rush University Library is located within the hospital. LHS is also a Regional Medical Library in the National Network of Libraries of Medicine, which covers ten states in the Greater 
Midwest Region. In addition to the LHS location in Chicago, there are site libraries in Peoria, Rockford, and Urbana, Illinois. Doing a practicum at these libraries gives the practicum student a more rounded experience.

\section{Background and Overview}

In December 2009, Chicago area health sciences librarians met to discuss issues relevant to health sciences librarianship. Rush University librarians had begun hosting a practicum student and had brought the student to the meeting. Both the librarians and the student answered questions about the practicum and expressed that it had been a positive experience. LHS librarians were interested in this idea and met with the Rush librarians to explore how they could collaborate together on a practicum. Together, LHS and Rush librarians wrote a description of the practicum and advertised it on library school internship opportunity websites. Prospective candidates were interviewed jointly by the librarians during the summer of 2010. Once the student was selected, the librarians determined which aspects of librarianship they would cover during the practicum as well as how it would be logistically implemented. The inaugural practicum occurred during the fall semester of 2010, and the student who was selected chose to do the practicum without receiving academic credit due to administrative reasons.

\section{The Process: The Challenges of Time, Space, Staff, and Resources}

Among the many details to consider for such an undertaking was the practical one of time: How much time would the librarians realistically be able to provide a student in order to achieve the optimum experience? The primary focus from the beginning was the 
student experience; the practical benefit to the libraries were a secondary, though still important, focus.

As a guideline, it was noted that if the student was taking the practicum for credit, the library school program required 120 hours of experience a semester. This number then was divided in half so that over the course of a twelve week semester, each library would host the student for six weeks, with the student working an average of two days a week, for a total of 10 hours per week. This was a time commitment that not only fully met the student's academic need, but was also more manageable for a busy library than a full-time or even half-time practicum arrangement. Further, with two libraries involved, the feedback from one library to the other during the practicum enabled an easier adjustment for the supervisors in terms of understanding the student's areas of strengths. Projects and training could much more easily be planned for in such an environment.

It was important to prepare and involve any staff members who were interested in contributing to the student's experience. Once interest was assessed, by a simple e-mail message to all staff, it was assured that at the very least the student would have a chance to interview staff members about their particular jobs within the library. Public Services staff were the most involved in the mentoring and training of the student, including service desk workers who were encouraged to help the student with the intricacies of serving patrons in person, by phone, e-mail, instant messaging, or texting. If the student had a particular interest in areas outside of the Public Services department, such as Archives, a more involved tour was arranged. The time invested in preparing the entire 
library staff for the arrival of the practicum student made for a more enriching experience for all involved.

Another consideration is the actual physical workspace available to the student. The practicum is meant to be as integrated as possible into the structure and routine of the library's daily activities. Having a dedicated workspace that includes a desk, chair, computer, and phone for the student invites the perception to the student and the library staff that this position is important and valued. Also, if discussions or impromptu meetings need to take place with the student, conducting those events within the practicum space saves time and the disruption of finding another meeting space. A dedicated space also gives the student an important sense of authority over the work she is providing the library and even over her presence within the library. These measures helped to ensure the student's integration within the library and avoided this particular negative outcome of Sargent, Becker, and Klingberg's study.(3)

Spending the time on staff buy-in as the library prepares to host a practicum student is a wise investment in other areas as well. The library staff gets a chance to think about how they want to interact with the student; they also get a chance to mentally prepare for a new person working alongside them. In addition, staff are invited to offer suggestions and ideas for ways in which the student might be able to contribute to improving library processes. Not only does this exercise help improve library function, but it also enables the current staff to envision possible solutions to problems they may be encountering. This provides the coordinating manager with ideas for future library-wide projects as well as projects for the incoming practicum student. 
When possible, it makes good sense to provide a junior librarian with very valuable mentoring and supervisory experience by pairing them with the practicum student, overseen by the coordinating manager.

If it is not possible to provide a monetary stipend for the student's time, it is important that this is clearly understood by the student during the interview process. At the same time however, depending on the institutions involved, perquisites, such as free parking, access to library resources, and networking opportunities might substitute for a financial stipend.

If the student chose to pursue academic credit, the librarians would have been able to set aside time to meet together with the student and the academic advisor to discuss the format of the practicum and learning goals and provide any assessments the degree program might require. This is always an interesting area for discussion among education theorists(5) given that the student is paying the school to work for free in a third-party setting. However, this is where the Master's of Library and Information Science (MLIS) programs and the practicum settings must have a dialogue about the benefits to all concerned. The student undoubtedly gains valuable experience and contacts, the practicum setting(s) gains a voice in the training and education of future librarians, and the academic program gains good public relations when it engages responsibly and in good faith with such an endeavor.

\section{Student Projects and Program Accomplishments}

The student was assigned complementary projects at each of the institutions in order to provide for a well-rounded experience and to take advantage of the unique 
aspects of each library. Whenever possible, the librarians avoided assigning projects that were simply rote or not useful for substantive learning, as the focus was on the student as well as the libraries gaining value from the projects.

The student was introduced to the reference desk at Rush, and built on that exposure at LHS, where she eventually took on solo reference desk shifts and also provided instant messaging and texting services for LHS patrons.

At both institutions, the student created research and subject guides using Springshare's LibGuides(6) platform, a content management system that allows libraries to connect with patrons and share information online. The student started with a simple guide and moved on to create guides with more complexity. The topics for the guides were chosen based on the particular library's need, so that the guides created could be of use to library staff and patrons long after the student's tenure.

Another focus was teaching: the student participated in database workshops at both institutions and solo-taught a PubMed workshop at Rush. The PubMed workshop was one of a series of workshops open to anyone with a Rush affiliation interested in learning more about library resources; these are usually attended by faculty, staff, and students. The student also observed a one-on-one consultation session with a LHS patron. Individual consultations are offered at LHS as a way to introduce library resources to patrons and to provide personalized assistance with patron research.

The student benefited from site-specific meetings as well. The student was introduced to the Morning Report meetings at Rush, and was able to attend most of the monthly cycle of the Internal Medicine Morning Reports, providing exposure to how a 
librarian in a hospital setting might interact with patrons. The student attended meetings at LHS such as the LHS outreach meetings and research discussion meetings.

Other projects included organizing LHS's Delicious page,(7) developing onesheet American Psychological Association and Modern Language Association style guide references, and assisting with Rush's serials migration project. At both libraries, the student was asked to provide feedback on existing processes and procedures as someone with a unique perspective: a quasi-proxy for patrons as well as someone with librarianship training. The student wrote a weekly summary of her experience to give the librarians her perspective of the practicum. The student also gave a final presentation to library staff from each institution at the end of the semester which outlined her experiences.

The libraries benefited in a number of ways. The practicum student brought new talent, skills, and insight to the libraries. Projects that were well-suited to the student's talents and the libraries' needs were brought to fruition. The libraries also benefited from the dialogue they had with each other regarding the student, and in this way were able to build on the student's work from one library to the other. Librarians and staff got involved in training and the opportunity to select, interview, and "hire" a new person for the library. When the libraries brought the student to meetings outside of the library, as with Rush's Morning Report and other such meetings, others within the institution were introduced to a person who was studying for an MLIS and the active role its own library was taking in the student's education. With a student who might be taking the practicum for credit, the libraries would also get an opportunity to discuss and influence what they 
viewed as important in the education of a health sciences librarian during dialogue with the student's academic advisor.

\section{The Future of the Rush-LHS Collaboration}

Librarians from both institutions will continue hosting one or two practicum students a year. They will meet periodically to refine the practicum based on student feedback. They will also explore different methods of assessing the practicum such as a standardized exit interview and conducting a longitudinal follow-up survey within the next five years.

Currently, the majority of prospective students for this joint practicum have been gathered from one local library school. With the availability of distance education programs to obtain library degrees, there may be a larger student population available that could take advantage of this opportunity. The librarians involved in this project would like to explore other options for advertising the practicum, such as professional networking sites, LinkedIn,(8) or working with library associations headquartered in the Chicagoland area.

\section{Conclusions}

The Rush-LHS partnership shows that a joint practicum can introduce collaboration between health sciences libraries with different environments. A student gains a full semester of experience, while the mentoring librarians are able to provide more quality time and attention to the student due to the short six-week time span at each institution. Librarians are able to mentor a library school student, who in turn gives librarians a fresh perspective on their workplace. The library school student is able to 
network and gain valuable workplace experience for his or her future career, gaining an understanding of multiple institutions. Hospital librarians with busy schedules may use this type of practicum as an opportunity to strengthen bonds between other hospitals or academic institutions. In this way, they can give back to their profession, showing future librarians that health sciences librarianship is a viable career choice. 


\section{References}

1. Smith LC. Interdisciplinary multinstitutional alliances in support of educational programs for health sciences librarians. Bull Med Libr Assoc. 1996 Oct; 4(4): 560-68.

2. Scherrer CS. Evaluating a health sciences library residency program: What have we learned? J Med Libr Assoc. 2010 Oct; 98(4): 300-2.

3. Sargent AR, Baker BW, Klingberg S. (2011). Incorporating library school interns on academic library subject teams. J Acad librariansh. 2011 Jan; 37(1): 28-33.

4. Illinois Department of Public Health, Health Systems Development. (2009). Individual Hospital Profiles by Hospital Name. http://www.idph.state.il.us/about/hfpb/pdf/ AHQ2009 Hospital Profile.pdf (29 Jul. 2011).

5. Wickersham, C., \& Westerberg , C. (2011, April 24) Internships Have Value, Whether or Not Students Are Paid. The Chronicle of Higher Education. http://chronicle. com/article/Internships Have-Value/127231/ (cited 2011 July 29).

6. Springshare LibGuides. (2011). http://www.springshare.com/libguides/ (29 Jul. 2011).

7. Delicious. (2011). http://www.delicious.com/ (29 Jul. 2011).

8. LinkedIn. (2011). http://www.linkedin.com/ (29 Jul. 2011). 